\title{
DE FIELES VASALLOS. LA TRANSICIÓN DEL RÉGIMEN DE TENENCIAS AL DE LAS ALCAIDÍAS Y MERINDADES EN EL REINO DE NAVARRA: EL GOBIERNO DEL CASTILLO DE ESTELLA A COMIENZOS DEL SIGLO XIII
}

\author{
Ander Salinas Garrido \\ Universidad del País Vasco / Euskal Herriko Unibertsitatea
}

\begin{abstract}
Resumen: Desde finales del siglo pasado, una nueva línea de interpretación encabezada por los historiadores Eloísa Ramírez Vaquero y Ángel Juan Martín Duque se inclina establecer la puesta en marcha del sistema de alcaidías y merindades en Navarra antes de la llegada de la dinastía de Champaña en 1234. Gracias al análisis de la documentación recogida sobre todo por José María Lacarra en la Colección diplomática de Irache. Volumen 1 (958-1222), creemos que somos capaces de situar, con mayor firmeza, los antecedentes del nuevo régimen, como mínimo, a comienzos del siglo XIII, esto es, en el reinado de Sancho VII el Fuerte. Nuestro objeto de estudio será la localidad de Estella, donde se observa un fenómeno muy curioso: desde el inicio del siglo XIII desaparece por completo la figura del tenente, quedando solo el alcaide del castillo. De hecho, el último tenente constatado propiamente dicho fue Diego López de Haro, señor de Vizcaya, en 1201-1202.
\end{abstract}

Palabras clave: Sancho VII, Estella, feudalismo, vasallaje, castillo.

ABOUT FAITHFUL VASSALS. THE TRANSITION OF THE REGIME OF «TENENCIAS» TO THE DISTRICTS AND CASTLES' GOVERNORSHIP ONE IN THE KINGDOM OF NAVARRE: THE GOVERNMENT OF ESTELLA'S CASTLE AT THE BEGINNING OF THE $13^{\text {TH }}$ CENTURY

Abstract: Since the end of the last century, a new interpretation line supported by the historians Eloísa Ramírez Vaquero and Ángel Juan Martín Duque would establish the beginning of the system of alcaidias and districts in Navarra before the arrival of the Champaña dynasty in 1234. Thanks to the analysis of the documentation collected mainly by José María Lacarra in the book Colección diplomática de Irache. Volumen 1 (958-1222), we believe that we are able to place, with great conviction, the antecedents of the new regime, at least, at the beginning of the $13^{\text {th }}$ century, that is, in the reign of Sancho VII el Fuerte. Our object of study will be the town of Estella, where a very curious phenomenon is observed: since the beginning of the13th century, the figure of the «tenente» completely disappears, only leaving the governor of the castle. In fact, the last properly verified «tenente» was Diego Lopez de Haro, Lord of Vizcaya, in 12011202.

Key words: Sancho VII, Estella, feudalism, vassalage, castle.

\footnotetext{
* Entregado: 15/05/2018. Aceptación definitiva: 08/11/2018. El autor es becario del programa predoctoral del Departamento de Educación del Gobierno Vasco.
} 


\section{INTRODUCCIÓN}

La importancia del castillo medieval en Navarra como centro político, económico y de dominación social se da por supuesta en los numerosos trabajos científicos llevados a cabo a lo largo del siglo XX y principios del XXI. Sin embargo, una somera revisión de la historiografía pone en evidencia la necesidad de la elaboración de un estudio sistemático y actualizado sobre el régimen jurídico de las fortificaciones de este territorio, aspecto hasta el día de hoy muy poco valorado por los historiadores. En este sentido, más allá de enumeraciones muy generales - y superficiales-, no hay apenas ningún trabajo completo al respecto para el reino de Navarra entre los siglos XII y XIII ${ }^{1}$.

Desde época altomedieval, el reino de Pamplona, que desde 1162 se llamaría «reino de Navarra», estaba dividido en un considerable número de circunscripciones territoriales menores. De acuerdo a la historiografía relativa a este territorio, debemos situar el origen de tal sistema a inicios del siglo X, más concretamente en el reinado de Sancho Garcés I (905-925). Generalmente, según el esquema más difundido, en muchos de los distritos se situaba una fortaleza o castillo el cual funcionaba como centro organizativo de los mismos. La custodia de estas circunscripciones territoriales recaía sobre los barones integrantes de la alta nobleza relacionados con el monarca: los denominados «tenentes». Estos, a su vez, contaban bajo su mando con un responsable de la guarnición del castillo. Inicialmente, los tenentes eran meros representantes del poder regio, del que emanaban sus facultades y prerrogativas. Con la tenencia disfrutaban de una serie de facultades de control, defensa y gobierno — no siempre bien conocidas en sus detalles - y del derecho a percibir determinadas rentas, compartidas con el monarca, su señor. A cambio de esta dotación se esperaba de ellos la prestación de servicios al rey, militares en especial.

Con el tiempo, ya entrado el s. XI, en especial desde el reinado de Sancho IV de Peñalén (1054-1076) conforme este grupo de barones gana capacidad de acción y de negociación colectiva frente al monarca en tierras del reino de Pamplona, pasarían a ser vasallos muy celosos de sus derechos y prerrogativas frente al monarca. A partir de aquí surgiría una fuerte tensión. El deseo de aferrarse a estas facultades generará con el tiempo que los señores pretendan consolidar su disfrute y convertirlas en derechos transmisibles a sus familiares. Tal pretensión respondía al deseo de esta elite de obtener un encumbramiento social, el ejercicio de un poder banal y la posesión de los castillos. Todo ello conllevó en un primer momento a un decaimiento del orden público y consecuentemente un ascenso intensificado de la violencia.

\footnotetext{
${ }^{1}$ Dentro de la escasez de la producción historiográfica, encontramos varios sobre las tenencias entre los siglos X y mediados del XIII, entre los que destacan los estudios de Aitor Pescador Medrano, José Luis Orella Unzué, Carlos Laliena Corbera, José María Lacarra de Miguel, Eloísa Ramírez Vaquero, Ángel Juan Martín Duque, José Ángel Lema Pueyo y Alberto Cañada Justé. Para épocas posteriores, tenemos fundamentalmente los trabajos de Juan José Martinena Ruiz, María Raquel García Arancón y Javier Zabalo Zabalegui.
} 
Durante la etapa comprendida entre 1150 y 1270, se produce una nueva transformación. Entre los reinados de Sancho VI (1150 - 1194) y Sancho VII (11941234) y, sobre todo, con la instauración de la dinastía de Champaña bajo Teobaldo I (1234 - 1253) y Teobaldo II (1253 - 1270), se cambia el sistema administrativo basado en las tenencias para lograr una mejora del gobierno y la extensión de la justicia. A través de esta reforma en la administración territorial, los grandes barones del reino fueron apartados de los principales cargos administrativos. Así, el tenente tradicional desaparece y queda el alcaide como mero encargado de la custodia del castillo, lo que genera un cambio en la naturaleza de sus funciones y en su régimen jurídico. Al mismo tiempo, determinadas funciones de gobierno y control se transfieren al merino, figura heredada de épocas anteriores, pero cuyo papel se afianza y desarrolla, principalmente, en el s. XIII tras la creación de distritos de administración territoriales más extensos que los anteriores: las merindades.

\section{DEFINICIÓN DE LA TENENCIA}

Encontrar una definición completa de lo que supone una tenencia en la historiografía no es tarea fácil. Debido a los escasos testimonios de los documentos de la época pocos han sido los historiadores que se han atrevido a definir dicha institución, así como explicar las características de la misma.

Uno de estos investigadores es Aitor Pescador, quien nos proporcionó una de las definiciones más precisas y acertadas de las tenencias: «circunscripciones territoriales menores donde un barón cumple ciertos deberes, tanto públicos como privados, y posee ciertos derechos concedidos por mano del rey» ${ }^{2}$. Dicho en otras palabras, el reino estaba fragmentado en un determinado número de distritos administrativos — variable a lo largo de su existencia - para un mejor gobierno, defensa y control de los diferentes territorios locales, cuya soberanía se delegaba generalmente a un aristócrata, el comúnmente llamado tenente (aunque también hay constancia de miembros de la nobleza más modesta) ${ }^{3}$. Inicialmente son representantes del poder real en los distritos, aunque con el tiempo, ya entrado el s. XI, concretamente bajo el reinado de Sancho IV de Peñalén (1054-1076), las características de tal responsabilidad irán evolucionando. Además, solían contar bajo su mando con un responsable de la guarnición del castillo.

Siguiendo los esquemas más clásicos, que siguen la opinión de José María Lacarra, las tenencias estaban configuradas por un núcleo fortificado y un pequeño distrito territorial a su alrededor, en las que podían incluirse villas y/o explotaciones

\footnotetext{
${ }^{2}$ Pescador Medrano, A., «Tenentes y tenencias del Reino de Pamplona en Álava, Vizcaya, Guipúzcoa, La Rioja y Castilla (1004-1076)», Vasconia: Cuadernos de historia-geografía, 29, (1999), p. 108.

${ }^{3}$ En la Alta Edad Media se utilizaba la palabra seniores para hacer referencia a los tenentes, es decir, a los agentes del poder real que gobernaban las villas, distritos o los castillos en nombre del rey. Ver LARREA CONDE, J. J., La Navarre du IVe au XIIe siècle: peuplement et société, De Boeck \& Larcier, ParísBruselas, 1998, pp. 226-227.
} 
agrarias $^{4}$, aunque también existían excepciones, casos de tierras sin poblaciones de importancia en los que la tenencia abarcaba una extensión de terreno superior a lo descrito, como la Vizcaya, Guipúzcoa o Baztán de inicios del siglo XI ${ }^{5}$.

Como señala el citado autor en su artículo titulado Honores y tenencias en Aragón. Siglo XI, dentro del reino de Aragón (recuérdese que a partir de 1076 y hasta 1134 está vinculado dinásticamente con el reino de Pamplona) aparecen tres tipos de dominios: el territorium regni, integrado por una serie de unidades políticas de entidad mayor que en distintos momentos y circunstancias políticas han ido a caer bajo dominio del rey, el honor regalis y, por otro lado, las propiedades alodiales de los barones algunos de los cuales concedidos por el rey-. Es en ese honor regalis donde se delimitan las tenencias, un conjunto de circunscripciones territoriales que el rey entrega a sus barones para ser gobernados según concesión beneficiaria, más un conjunto de bienes diversos que dependen del monarca.

Según el mencionado medievalista, quien interpreta las tenencias como una relación administrativa, son una concesión típica navarro-aragonesa constituida por distritos territoriales que el monarca entrega a los barones para el cumplimiento de ciertos deberes públicos o privados, más otra masa de bienes —aldeas, campos, yermos o cultivados, iglesias, monasterios, etc. - que no pueden ser reclamados por nadie como propiedad alodial ${ }^{6}$. Esto es, su concesión era temporal para «el cumplimiento de unos deberes —o servicios - fundamentales, pero sin que estos pasen a integrar el patrimonio del barón» 7 .

Siguiendo a Lacarra y con él a otros historiadores, la tenencia aglutina dos tipos de instituciones: por un lado un distrito, a menudo presidido por una fortaleza, y, por otro lado, una honor, beneficio o prestimonio que el rey concede a miembros de la alta nobleza para defenderla, gobernarla y administrarla ${ }^{8}$. Otra cosa muy distinta es que, tras los escritos del historiador Lacarra de Miguel, estos conceptos se hayan utilizado como sinónimos ${ }^{9}$. Así, no fue otro que Juan José Larrea Conde quien puso el debate sobre la

\footnotetext{
${ }^{4}$ Laliena Corbera, C., La formación del Estado feudal. Aragón y Navarra en la época de Pedro I, Instituto de Estudios Altoaragoneses, Huesca, 1996, p. 233.

${ }^{5}$ Goyhenetche, M.; Jimeno, R.; Pescador, A.; UrZAinqui, T., Vasconia en el siglo XI. Reinado de Sancho III, el Mayor, rey de Pamplona (1004-1035), Pamiela, Pamplona, 2004, p. 57 y PESCADOR MEDRANO, «Tenentes y..., pp. 108-109.

${ }^{6}$ LaCARra de Miguel, J. M., «Honores y tenencias en Aragón. Siglo XI», en Colonización, parias, repoblación y otros estudios, Anubar, Zaragoza, 1981, p. 117.

${ }^{7}$ LACARRA De Miguel, J. M., «Honores y tenencias..., pp. 118-119.

${ }^{8}$ LACARRA DE Miguel, J. M., «Honores y tenencias..., pp. 119-120; Orella UnZUÉ, J. L., «Nacimiento de Gipuzkoa como tenencia navarra de frontera», Lurralde: investigación y espacio, 34, (2011), p. 190.

${ }^{9} \mathrm{El}$ historiador menciona varios tipos de concesiones reales a los barones, entre los cuales la pieza central de la cohesión de la clase aristocrática en torno a la monarquía sería la concesión de honor a cambio de servicios. En este modelo, el honor es sinónimo de tenencia, es decir, la guarda de un castillo o el gobierno de un distrito: su posesión implica la percepción de la mitad de los ingresos fiscales en el distrito y una parte de los ingresos de justicia. En contraprestación, el tenente tendrá el deber ante el rey de adiutorium et consilium, como se indica en los documentos, más las obligaciones de las que sería responsable por ser vasallo del rey. En este sentido, apuntamos que a pesar de que la historiografía clásica usara a partir del trabajo de Lacarra ambos aspectos como sinónimos, es decir, la guarda de un castillo y
} 
mesa, tras afirmar que ninguna fuente acredita que la tenencia de distritos funcione de acuerdo con el régimen de concesiones beneficiarias y de servicios vasalláticos ${ }^{10}$. Para él, la tenencia, la cual vincula con el servicio de guarda de castillos y distritos, es un concepto diferenciado de los honores y de las concesiones beneficiarias. El defecto de los historiadores clásicos ha sido el de usar indiscriminadamente y hacer equivalente unos términos y conceptos, la tenencia y el honor, que, en origen, son diferenciados. Pues el uno parece que debe ser entendido, en principio, como un servicio, mientras que el otro es un beneficio, esto es, un conjunto de derechos y rentas que Lacarra estima en la mitad de las unidades que produjera la honor real y que se fundamenta en la percepción de una serie de tributos sobre la tierra, derechos, justicia y caloñas ${ }^{11}$.

Dicho lo cual, Larrea Conde cree que debemos entender la tenencia ante todo como un servicio, la cual va a asimilar la honor como recompensa de la fidelidad del noble. Pero honor y tenencia son cosas distintas. De hecho, la honor es un término genérico que designa más bien un conjunto de bienes — generalmente inmuebles - y rentas, que puede referirse tanto al alodio, como a la recompensa por la fidelidad, o como salarios para la prestación de un servicio ${ }^{12}$. Bienes y rentas que acrecentaban el prestigio del poseedor y le proporcionaban riqueza suficiente para que pudiera ejercer su función militar contra cualquier enemigo del soberano ${ }^{13}$.

En este sentido, si bien es cierto que el medievalista Carlos Laliena vincula la palabra honor al de «oficio público», advierte que no es correcto exagerar tal caracterización, puesto que se puede incurrir en ver en las honores el desarrollo de un servicio administrativo, lo que conllevaría cometer, sin lugar a dudas, un anacronismo ${ }^{14}$.

El citado historiador se inclina en definir la honor como un feudo concedido por parte del rey a sus barones ${ }^{15}$. A cambio de los servicios de consilium (consejo en la curia del rey) y adiutorium (ayuda militar) los aristócratas eran recompensados con la entrega de tenencias y honores. A través de estas concesiones o feudos, los cuales no se podían retirar salvo la ruptura de la fidelidad del barón (básicamente, por cometer un acto de traición), el noble tenía derecho al usufructo del distrito. Desde el punto de vista de los barones el rey tiene, entre otros, un deber respecto a ellos: el de darles honores y el no arrebatárselos de cualquier manera, la cual supone la existencia de causas por las cuales puede hacerlo y una posible tendencia del rey a quebrantar ambos aspectos. Del

el gobierno de un distrito, la verdad es que responden a realidades diferentes. Ver LARREA CONDE, J. J., La Navarre..., pp. 361 y ss.

${ }^{10}$ LARREA CONDE, J. J., La Navarre..., p. 363.

11 PeÑa Bocos, E., «Alfoces y tenencias: la Rioja», en Del Cantábrico al Duero: trece estudios sobre organización social del espacio en los s. VIII a XIII, GARCÍA DE CORTAZAR, J. Á. (coord.), Universidad de Cantabria, Santander, 1999, pp. 389-393.

12 LaRrea CONDE, J. J., La Navarre..., pp. 361-365.

${ }^{13}$ LALIENA CORBERA, C., La formación..., pp. 232-233.

${ }^{14}$ LALIENA CORBERA, C., La formación ..., p. 235.

15 Laliena CORBERA, C., La formación..., pp. 235-236; LALIENA CORBERA, C., «Una revolución silenciosa. Transformaciones de la aristocracia navarro-aragonesa bajo Sancho el Mayor», Aragón en la Edad Media, 10-11 (1993), pp. 284-285. 
lado del rey, en cambio, existe una obligación desarrollada en dos direcciones: dar y no quitar, es decir, que el vínculo existente entre el rey y el barón tiene como consecuencia la entrega obligatoria del primero al segundo; este, por su parte, disfruta de una plena libertad de aceptar o no, y en caso de aceptar, tiene el derecho de dejar o conservar la tenencia con la única limitación de no poder abandonarla mientras hubiera una guerra. Es decir, que el rey no puede obligarle a la aceptación de honores y, por tanto, a la prestación de servicios que se deducen de la tenencia. La verdad es que las honores podían ser muy lucrativas, pero también una carga grave, si por ejemplo tenemos en cuenta que la situación de frontera con el Islam en el siglo XI era de escasa movilidad y por consiguiente, de pocas opciones de beneficios económicos relacionados con la guerra, por lo que los barones no quieren verse obligados a aceptarlas ${ }^{16}$. Incluso algunos textos parecen indicar la posibilidad de que los nobles pudieran devolver las honores previamente aceptadas, con sus castillos, tierras y rentas, al rey ${ }^{17}$. Con todo, la aceptación de una honor conllevaba la obligación — bajo pena de castigo - de tener que defenderla de cualquier enemigo del monarca ${ }^{18}$.

Analizando las concesiones de las honores a los diferentes barones a lo largo de las décadas, se puede decir que existía una norma de heredabilidad de las honores dentro del linaje familiar - aunque no siempre de padres a hijos- . No obstante, como quedará patente en los documentos de los siglos XII y XIII, a pesar de que miembros de diferentes generaciones de un linaje lograran el control de la misma honor, no se dio una patrimonialización ${ }^{19}$, lo que evitaba el enraizamiento de los barones. De hecho, el rey tenía la capacidad para limitar el poder de los barones, desplazándolos de sus honores y colocando a otros, tanto en vida como interviniendo en la trasmisión hereditaria ${ }^{20}$. Para garantizar la supremacía y el patronazgo del monarca, era imprescindible que la trasmisión de las honores no se produjera de forma totalmente automática al heredero del tenente difunto, sino que el soberano dispusiera de posibilidades de alterar la investidura al noble que más creyera oportuno. Dicho de otra manera, que conservara un cierto grado de libertad en su asignación ${ }^{21}$.

Como hemos visto, las honores eran concesiones beneficiarias que el rey entregaba a sus barones a cambio del ejercicio de unos servicios, pero sin que estas pasaran a formar parte del patrimonio propio de los nobles. Es por esto mismo por lo que el historiador medievalista Ángel Juan Martín Duque cree que no deben definirse las honores como «feudos» en sentido estricto de la palabra. Aunque, advierte, eso sí, «cierta tendencia a vincularlas al conjunto de linajes de barones del reino, práctica sin

\footnotetext{
${ }^{16}$ LACARRA DE Miguel, J. M., «Honores y tenencias..., pp. 136-137.

${ }^{17}$ LALIENA CORBERA, C., La formación..., p. 244.

${ }^{18}$ LALIENA CORBERA, C., La formación ..., p. 244.

${ }^{19}$ LALIENA CorberA, C., «Una revolución silenciosa..., p. 489.

${ }^{20}$ LALIENA CORBERA, C., La formación ..., p. 254.

${ }^{21}$ LALIENA CoRBera, C., La formación ..., p. 233.
} 
duda consuetudinaria que se llegaría a reivindicar como derecho adquirido que comprometía al monarca» 22 .

Por otro lado, debemos de ser cautelosos a la hora de valorar la distribución de las honores, que los historiadores solemos reconocer en las poblaciones enumeradas en los escatocolos de los documentos reales junto al nombre de los tenentes. Según Carlos Laliena estas menciones solo responderían a las honores más importantes y prestigiosas que ostentaban los tenentes como, por ejemplo, aquellas que incluían importantes fortalezas para la defensa del territorio en territorio de frontera. Es por ello por lo que no se puede descartar que además de las tenencias contabilizadas a partir de los diplomas reales no hubiera otras honores de menor calado en posesión también de los nobles $^{23}$. De hecho, las investiduras de las honores no exigían la redacción de ningún tipo de documento. Podemos pensar que como la entrega de una honor era una concesión de carácter temporal, esto es, no involucraba la propiedad, que seguía siendo del rey, por lo que las ceremonias públicas de homenaje cumplían sobradamente el requisito de crear mutuas obligaciones entre el rey y el tenente ${ }^{24}$.

Los barones, al recibir una tenencia, estaban obligados a prestar homenaje al rey de Navarra. En virtud de dicho homenaje, se reconocían como vasallos suyos, y por consiguiente se comprometían por su honor a guardarle fidelidad como su señor y a defender en todo momento la concesión recibida ${ }^{25}$. En este sentido, quisiéramos apuntar que - por desgracia - apenas nos han llegado testimonios relativos a este tipo de compromisos. Es posible que, como estamos todavía ante una cultura basada principalmente en la oralidad, el uso de la escritura en muchos actos jurídicos y solemnidades sociales estuviese algo limitado, con lo que el acto de otorgamiento se desarrollase de viva voz sin dejar ningún rastro escrito. Tampoco podemos descartar que el ritual fuera en aquella época tan corriente y conocido que apenas aflorase en los documentos $^{26}$. Ignoramos las características específicas de este tipo de rituales, pero por lo que se intuye de ciertos documentos, la esencia de ese ritual la constituía algún gesto con las manos y un beso ${ }^{27}$.

En definitiva, y como apreciamos, las palabras tenencia y honor son una realidad muy compleja que a día de hoy sigue siendo un tanto desconocida.

\footnotetext{
${ }^{22}$ Martín DuQue, Á. J., «Nobleza navarra altomedieval», Príncipe de Viana, 227, (2002), p. 678.

${ }^{23}$ LALIENA CORBERA, C., La formación ..., pp. 236-237.

${ }^{24}$ LALIENA CORBERA, C., La formación..., p. 234.

${ }^{25}$ Martinena RuIZ, J. J., Castillos reales de Navarra (siglos XIII-XVI), Gobierno de Navarra, Pamplona, 1994, pp. 125-127.

${ }^{26}$ MARTín DuQUE, Á. J., «Nobleza navarra altomedieval», en La nobleza peninsular en la Edad Media. VI Congreso de Estudios Medievales, Fundación Sánchez Albornoz, Ávila, 1999, p. 241.

${ }^{27}$ Laliena CoRBERA, C., La formación..., p. 234.
} 


\section{LA ALCAIDÍA BAJO EL REINADO DE SANCHO VII.}

Como se ha detallado anteriormente, en muchos de los distritos se situaba una fortaleza o castillo el cual funcionaba como centro organizativo de los mismos. En época de Sancho VII el Fuerte su custodia recaía, como se indica en los documentos de la época, sobre el ricohombre que disfrutaba de la honor por mano del rey. Este a su vez estaba facultado para ceder su custodia a un infanzón o caballero que toma el nombre de alcaide o castellano $^{28}$.

Podemos decir que la tenencia generaba sus propias jerarquías; así, sabemos que la dirección de la custodia del castillo recaía sobre un hombre de confianza del tenente al que las fuentes aluden con el nombre de alcaide — «alcaid» «alcayt», «alcayet», «castellan alcalt»—o prestamero. Teniendo en cuenta la sociedad ante la que estamos, en la que imperan las relaciones feudo-vasalláticas, nos atrevemos a sugerir - a menos a título hipotético y con las máximas cautelas - que estos en algunos casos podían ser vasallos del tenente, al que le debían de haber prestado homenaje, por lo que, desde el punto de vista del rey, eran sub-vasallos, o lo que es lo mismo, vasallos de los vasallos $^{29}$. De esta manera, el alcaide dependía vasalláticamente del tenente, es decir, estaba en un nivel inferior al de este por lo que su dependencia más directa era con el tenente, no con el rey ${ }^{30}$.

Tal estado de cosas parece perdurar hasta el reinado de Sancho VII el Fuerte (1194-1234). Las pocas menciones existentes sobre el alcaide durante este período constatan su presencia en Caparroso ${ }^{31}$, Estella ${ }^{32}$, Funes $^{33}$, Gallur $^{34}$, Los Arcos ${ }^{35}$ y Puente la Reina ${ }^{36}$, aunque creemos que seguramente actuarían en casi todas las tenencias del reino. De hecho, tenemos constancia que en fechas posteriores, en concreto en el siglo $\mathrm{XIV}$, al frente de cada uno de los castillos (recuérdese que eran junto a las villas fortificadas los elementos en los que se vertebraba el sistema defensivo navarro) había

\footnotetext{
${ }^{28}$ GARCía ARANCÓn, M. R., Teobaldo II de Navarra, 1253-1270. Gobierno de la Monarquía y recursos financieros, Gobierno de Navarra, Pamplona, 1985, pp. 338 y 348.

${ }^{29}$ Sin embargo, como explica el medievalista Joseph Morsel la relación que estos guardianes de los castillos - y las guarniciones a su servicio, como veremos más adelante - tenían con el tenente es, en lo relativo a su naturaleza jurídica y a sus efectos sociales, desconocida en gran medida. Ver MoRSEL, J., La aristocracia medieval: el dominio social en Occidente (siglos $V$-XV), Universidad de Valencia, Valencia, 2008, pp. 131-132.

${ }^{30}$ LEMA PueYo, J. Á., Instituciones políticas del reinado de Alfonso I el Batallador, Rey de Aragón y Pamplona (1104-1134), Universidad del País Vasco, Bilbao, 1997, p. 166.

31 Jimeno Jurío, J. M.; Jimeno ARAnguren, R., Colección documental de Sancho VII el fuerte (11941234). Archivo General de Navarra, Pamiela, Udalbide, Euskara Kultur Elkargoa (Col. Obras completas de José María Jimeno Jurío, n. ${ }^{\circ}$ 8), Pamplona, 2008, doc. núm. 212.

32 Jimeno Jurío, J. M.; Jimeno ARANGUREN, R., Colección documental..., doc. núm. 244.

${ }^{33}$ Jimeno Jurío, J. M.; Jimeno ARANGUREN, R., Colección documental..., doc. núm. 247.

${ }^{34}$ Jimeno Jurío, J. M.; Jimeno ARANGUREN, R., Colección documental ..., doc. núm. 133.

${ }^{35}$ LaCARra de Miguel, J. M., Colección diplomática de Irache. Volumen 1 (958-1222), CSIC, Zaragoza, 1965, doc. núm. 238.

${ }^{36}$ LaCARra De Miguel, J. M., Colección diplomática ..., doc. núm. 229.
} 
un alcaide que debía residir en él con estabilidad ${ }^{37}$. Además, cabe plantearse que en muchas de estas fortalezas había una guarnición para defenderla que estaría al mando del alcaide, ya que, se nos hace difícil creer que un solo hombre podría defender y administrar un castillo. De todos modos, su presencia solo se hace constar, al menos, en el castillo de Urzante aunque no tenemos ningún tipo de referencia sobre el número de hombres ni de la cantidad total derivada de las rentas dirigidas a su mantenimiento ${ }^{38}$.

En la época que nos atañe, sabemos relativamente poco sobre las funciones concretas del alcaide, más allá de la de guarda del castillo. Se puede pensar que debía mantener también la guarnición en correcto estado, así como supervisar que el personal bajo su mando estuviera provisto de armas y vituallas adecuadas ${ }^{39}$.

La instauración de la dinastía de Champaña en el trono del reino significó el punto final del sistema de tenencias. Desde el siglo XII se fue produciendo una reforma paulatina en la administración territorial, una sustitución que se intensificó con la llegada de los monarcas franceses, a raíz de la cual las tenencias perderían su carácter administrativo, manteniéndose a partir de entonces como simples pagos o retenencias. Así, el tenente desapareció y quedó el alcaide como mero encargado de la custodia del castillo, en una relación directa con el monarca, lo que generó un cambio de sus funciones y en el régimen jurídico del castillo.

\section{LA GESTACIÓN}

Como se ha apuntado anteriormente, el régimen de tenencias y honores confiadas a los ricoshombres se mantuvo hasta la llegada de la Casa de Champaña al trono navarro. Este sistema constituyó una forma eficaz de gobierno, administración, ordenación y defensa de los diferentes territorios del reino durante la época de la guerra contra los musulmanes hasta finales del siglo XII, el cual ayudó a fortalecer y afianzar las fronteras meridionales del reino frente a los musulmanes y reinos enemigos ${ }^{40}$. Sin embargo, durante el reinado de Teobaldo I y, sobre todo, bajo Teobaldo II, vemos configurada una nueva geografía de merindades y bailías regias en sustitución de las antiguas tenencias ${ }^{41}$.

\footnotetext{
${ }^{37}$ En el caso de que un mismo alcaide tuviera bajo su cargo dos castillos, debía nombrar un lugarteniente para uno de ellos. Ver Zabalo Zabalegui, J., La administración del Reino de Navarra en el siglo XIV, Universidad de Navarra, Pamplona, 1973, p. 326.

38 Jimeno Jurío, J. M.; Jimeno ArAnguren, R., Colección documental..., doc. núm. 172; Lema PUEYO, J. Á., «Vasallaje y patrimonio: Sancho VII el Fuerte y el control de la nobleza navarra (1194-1234)», en Estudios en homenaje al profesor César González Mínguez, BAZÁn Díaz, I. (coord.), Universidad del País Vasco, Bilbao, 2015, pp. 166-167.

${ }^{39}$ ZABALO ZABALEGUi, J., La administración..., pp. 326-327.

${ }^{40}$ ORElla UnZUÉ, J. L., «Nacimiento de..., p. 191.

41 RAmírez VAQUero, E., «De los Sanchos a los Teobaldos: ¿Cabe reconsiderar la Navarra del siglo XIII?», en La Península Ibérica en tiempos de las Navas de Tolosa, EstePA DíEZ, C.; CARMONA RUIZ, M. A. (Coords.), Sociedad Española de Estudios Medievales, Madrid, 2014, p. 402.
} 
De acuerdo a la historiografía navarra tradicional ${ }^{42}$, tras la llegada de los primeros monarcas champañeses al trono de Navarra se produjo una reforma en la administración territorial del reino, siendo los tenentes paulatinamente reemplazados, en consecuencia, por agentes nombrados y remunerados directamente por el monarca: los alcaides y merinos. Con los reyes franceses se introducía en Navarra un concepto de soberanía nuevo, que se estaba extendiendo a su vez por toda Europa, cada vez más centralizado en la corte del rey ${ }^{43}$.

El que fue el primer rey navarro de la dinastía de Champaña, Teobaldo I, era también desde 1222 el cuarto conde de Champaña, donde se estaba robusteciendo el ejercicio de la administración en todas sus facetas. El reforzamiento del poder condal en tierras champañesas fue iniciado por su padre, Teobaldo III, durante su corto mandato (1198-1201), y seguido por su madre Blanca durante su minoría de edad (1201-1222) y por él mismo hasta el año de su muerte (1253). La implantación de esta nueva política pasaba por controlar y subordinar a los principales barones del territorio; para ello, regularon la construcción y el uso de las fortificaciones en tierras alodiales y supervisaron la disposición de feudos condales limitando el uso de las propiedades más importantes de los barones. Asimismo, los condes expandieron su dominio mediante la adquisición de castillos y propiedades estratégicas señoriales ${ }^{44}$. De esta manera, Teobaldo III de Champaña impuso su potestad directa sobre las fortificaciones señoriales. No se sabe con exactitud las razones que le llevaron a adoptar esta nueva política de castillos, pero según Theodore Evergates caben dos explicaciones: quizás porque quería consolidar su control sobre las familias nobiliarias como anticipación a las reclamaciones que hicieran las dos hijas de su hermano, el que fuera Enrique II de Champaña — predecesor en el cargo de Teobaldo III-, Filipa y Alicia de Champaña; otra posibilidad es considerarla una reacción a la ola de construcción de castillos que hubo en Francia en la década de 1190, edificados por los hijos pequeños de los principales barones del condado, cuya fidelidad correspondía en sus allegados más cercanos y no al rey. Estas redes familiares solían formar «ligas» armadas lo que provocaba numerosos problemas para la potestad condal ${ }^{45}$.

Así, desde Teobaldo III en adelante todo aquel que tuviera a su cargo un castillo debía convertirse vasallo del conde. Además, a partir de 1200 los barones empezaron a entregar los castillos que poseían (algunos habían sido entregados en feudos por él mismo, pero otros no) a Teobaldo III, aunque se desconoce de qué manera les indujo a ello o qué les concedió a cambio ${ }^{46}$. A partir de entonces casi todos los castillos y

\footnotetext{
${ }^{42}$ Hacemos referencia fundamentalmente a los historiadores María Raquel García Arancón y Juan José Martinena Ruiz.

${ }^{43}$ OrELla UnZUÉ, J. L., «Nacimiento de..., p. 213.

${ }^{44}$ EVERGATES, T., The aristocracy in the county of Champagne, 1100-1300, University of Pennsylvania Press, Philadelphia, 2007, p. 32.

45 Los únicos que se salvaban de este tipo de restricciones eran los grandes barones con estrechas relaciones con el rey. EVERGATES, T., The aristocracy..., pp. 35-36.

${ }^{46}$ Evergates, T., The aristocracy..., pp. 35-36.
} 
residencias fortificadas eran considerados cómo feudos condales directos, y muchos de ellos también entregables ante la demanda del conde ${ }^{47}$.

Para 1250 la subordinación de los nobles se había completado. De esta manera, los principales barones del condado habían pasado de señores que actuaban de una manera casi independiente en sus territorios, a ser totalmente subordinados a la potestad condal. No obstante, el control sobre la clase nobiliaria no quedó ahí; dejaron de participar en el gobierno de Champaña y Teobaldo III y su mujer Blanca de Navarra confiaron la administración del reino a clérigos y cargos profesionales nombrados y remunerados directamente por ellos con los que los barones debían tratar directamente. Aun y todo, debemos apuntar que Teobaldo IV continuó concediendo nuevos feudos a la nobleza en agradecimiento a sus servicios, feudos que habían sido confiscados o comprados a vasallos necesitados, pero en cuanto a la cantidad, estos eran notablemente muchos menos que los que concedieron sus predecesores. No obstante, desde Teobaldo III aumentaron la concesión de rentas feudales como forma de gratificación por los servicios prestados y aumentaron los feudos existentes para avanzar en su nueva política de castillos, especialmente para asegurar el homenaje vasallático de los señores poseedores de castillos y la conversión, por consiguiente, de los castillos y fortalezas alodiales en feudos condales ${ }^{48}$. En definitiva, en el condado de Champaña, durante los reinados de Teobaldo III, Blanca y Teobaldo IV, «las propiedades alodiales se desmilitarizaron». Por consiguiente, todo aquel que desease construir una fortaleza la debía tener como un feudo condal ${ }^{49}$.

Conociendo el antecedente champañés, es lógico pensar que cuando llegó Teobaldo I al reino de Navarra desconfiara del sistema de tenencias, ya que estas «usurpaban facultades propias del monarca, como la ejecución de la justicia, y que, al pretender intervenir en el gobierno del reino, representaban un peligro para la autoridad real» ${ }^{50}$. Es por ello por lo que el antiguo sistema de tenencias experimentaría, según los historiadores citados previamente, una radical transformación durante el reinado de Teobaldo I, evolucionando hacia otro más moderno a imitación del modelo francés, esto es, un sistema organizado sobre una base territorial más amplia y definida que las anteriores tenencias: la merindad ${ }^{51}$.

\footnotetext{
${ }^{47}$ Evergates, T., The aristocracy..., p. 42.

${ }^{48}$ EVERGates, T., The aristocracy..., p. 52 y 65.

${ }^{49}$ EVERGates, T., The aristocracy..., p. 67.

${ }^{50}$ García Arancón, M. R., La dinastía de Champaña en Navarra: Teobaldo I, Teobaldo II, Enrique I (1234-1274), Trea, Gijón, 2010, p. 57.

${ }^{51}$ En opinión de María Raquel García Arancón, esta reforma emprendida por el monarca champañés coincidió con la reordenación territorial de otros reinos, como Castilla y Aragón. En 1231 encontramos a tres merinos mayores castellanos y durante el reinado de Alfonso X (1252-1284) aparecen los adelantados de frontera, que en el siglo XIV reemplazan o se superponen a los merinos mayores. En Aragón, es durante el reinado de Jaime I cuando surgen los sobrejunteros, delegados del poder real. Así, las sobrejunterías se agruparon en el siglo XIV dando lugar a las gobernaciones. Ver GARCíA ARANCÓN, M. R., La dinastía ..., pp. 295-296.
} 
Sin embargo, otra línea interpretativa encabezada por los historiadores Eloísa Ramírez Vaquero y Ángel Juan Martín Duque empezó a analizar, desde finales del siglo pasado, el fenómeno de la transición del sistema de tenencias al de merindades desde una perspectiva muy distinta.

Lejos de considerar el año 1234, es decir, el del cambio dinástico, el momento en el cual va a aflorar un nuevo sistema (el de las merindades) por medio de la Casa de Champaña, Eloísa Ramírez plantea que la sustitución del régimen de tenencias fue un proceso lento que ya se estaba gestando desde por lo menos inicios del siglo XIII ${ }^{52}$.

De hecho, la figura del merino no aparecerá repentinamente con la llegada de los monarcas champañeses, sino que su existencia se constata desde, por lo menos, el siglo XII. Así, en una fecha tan temprana como el reinado de Alfonso I el Batallador (11041134) encontramos un tal García Ibáñez como merino de Funes, que cabría definirlo como una especie de intendente mayor de los dominios señoriales y derechos económicos de la Corona ${ }^{53}$. Siguiendo con la cronología, también se constatan merinos en los reinados de García Ramírez (1134-1150) y Sancho el Sabio $(1150-1194)^{54}$.

Durante el reinado de Sancho VII el Fuerte (1194-1234) parece que la figura del merino cobra mayor importancia si nos atenemos a los casos encontrados en la documentación. Así, a lo largo del reinado del rey Fuerte se contabilizan al menos cuatro merinos: Iñigo de Gomacín, merino del rey al menos entre 1203 y1232, Martín Pérez de Aranguren, Fortún de Arguiñano y Pedro Macua de Obanos. Estos oficiales servirían al rey en tareas de gestión de la monarquía, de su patrimonio y de la aplicación de justicia ${ }^{55}$.

A la vista de los datos proporcionados, es posible afirmar que el cargo de merino es efectivo en Navarra antes de la llegada de la dinastía de Champaña, por lo que cabría pensar que el nuevo sistema de merindades se va paulatinamente disponiendo desde, al menos, inicios del siglo XIII. O al menos, y en palabras de Eloísa Ramírez Vaquero, «se visibiliza notoriamente, se acentúa ${ }^{56}$. Sin embargo, debemos de tener en cuenta que la existencia de merinos no conlleva o condiciona, en consecuencia, la existencia de un organigrama de merindades perfectamente definido en todo el territorio para estas fechas. Quizá sería preferible pensar en el ejercicio del merino sobre áreas de influencia, determinadas por la abundancia de dominios y rentas reales que era necesario gestionar $^{57}$.

\footnotetext{
52 RAMÍREZ VAQUERO, E., «De los Sanchos..., pp. 402-403.

${ }^{53}$ Ramírez Vaquero, E., «De los Sanchos..., p. 403; MARTín DuQue, Á. J.; RAMírez VAQuero, E., «Aragón y Navarra. Instituciones, sociedad, economía (siglos XI y XIII)», en Historia de España Menéndez Pidal, Jover, J. M. (dir.), X-2, Madrid, 1992, p. 395.

${ }^{54}$ RAMÍREZ VAQUERO, E., «Los resortes del poder en la Navarra bajomedieval (siglos XII-XV)», Anuario de estudios medievales, 25-2, (1995), p. 434.

${ }^{55}$ RAMÍREZ VAQUERO, E., «De los Sanchos..., p. 403.

${ }^{56}$ RAMírEZ VAQUERO, E., «De los Sanchos..., p. 403.

${ }^{57}$ RAMÍREZ VAQUERO, E., «Los resortes..., p. 434 y LALIENA CORBERA, C., La formación ..., p. 280.
} 
Los merinos, los oficiales puestos directamente por el rey al frente de cada una de las diferentes merindades ${ }^{58}$, asumirían a partir de entonces el cometido que habían venido desempeñando anteriormente los tenentes ${ }^{59}$. Junto al merino, aparecerá en el reino de Navarra la figura del baile, con la función casi exclusiva de gestionar el patrimonio real, esto es, el cobro de las rentas. Se podría dividir su actuación en Navarra en dos planos diferentes. Por un lado, el baile colocado al frente de áreas de diversa consideración, como por ejemplo valles o comarcas, que respondería a una especie de delegado del poder real en la comarca. Se podría comparar su función como la de un «sub-merino». Por el otro, aquel baile situado en las cabeceras de las merindades y villas francas, pero no dependiente del merino, sino como un oficial paralelo

«que representa y protege los derechos del rey, ejecuta la justicia y mantiene el orden público en su distrito, pero que debe convivir con otros oficiales de vieja raigambre en la tradición del reino, que ya detentaban esas funciones en esos ámbitos y que no desaparecen: almirantes, prebostes y justicias» ${ }^{60}$.

Paralelamente, los castillos pasarían a estar a cargo de los alcaides, aunque a raíz del nuevo contexto, sugerimos que serían nombrados directamente por el rey, por lo que ahora dependerían del monarca, sin instancias interpuestas, y no del ricohombre a cargo de la tenencia como anteriormente ${ }^{61}$. Dicho lo cual, los alcaides dejarían de ser subvasallos del rey como en época de Sancho VII — recuérdese en la dependencia feudovasallática del alcaide hacia el tenente-, a ser vasallos directos del mismo. Su función era esencialmente militar, es decir, eran los responsables de la guarda del castillo en tiempos de paz y de su defensa en tiempo de guerra. A pesar de ello, los merinos también conservaban atribuciones militares. Juan José Martinena hace una matización muy interesante al respecto:

\footnotetext{
${ }^{58}$ Bajo el reinado de Teobaldo II aparecen claramente definidas las merindades de Tudela, Estella, Pamplona y Sangüesa, más el distrito de Ultrapuertos. Este último estaba formado por las regiones de Cisa, Baigorri, Osés, Mixa, Ostabares, Arbeloa, Irisarri, Yoldi y Armendáriz, aunque no constituyó en los siglos medievales una merindad, denominación que no apareció regularmente hasta que aquellas tierras se incorporaron, desde 1530, a los estados franceses de los reyes de la casa de Albret. De tal manera que la administración de Ultrapuertos se realizaba por oficiales regionales (el castellano de San Juan Pie de Puerto, y los bailes de Mixa y Ostabares y de la Bastide-Clairence) si bien existía un merino en cada uno de los distritos de Cisa, Baigorri, Osés y Arberoa. Ver MonREal ZiA, G.; Jimeno ARANGUREn, R., Textos histórico-jurídicos navarros. Historia antigua y medieval. T. 1, Gobierno de Navarra, Pamplona, 2008, pp. 653-654. En 1410 se añade la merindad de Olite a este sistema. Ver GARCía ARANCón, M. R., La dinastía..., p. 294.

${ }^{59}$ MARTinena RuIZ, J. J., Castillos reales de Navarra (siglos XIII-XVI), Gobierno de Navarra, Pamplona, 1994, p. 69.

${ }^{60}$ RAMIREZ VAQUERO, E., «Los resortes...», pp. 435-436.

${ }^{61}$ El quizás mayor conocedor de los castillos medievales navarros, Juan José Martinena, defiende la idea de que también podían ser nombrados por alguno de los ricohombres del reino. Sin embargo, no somos capaces de interpretar si lo que realmente quiere transmitir es que esta realidad podía darse hasta la desaparición de los tenentes en 1238, o, por el contrario, que los barones en la práctica sí podían nombrar alcaides aunque estos dependieran y fueran remunerados directamente por el monarca. Ver MARTINENA RuIZ, J. J., Castillos reales..., p. 69.
} 
«Conviene distinguir entre defensa estática y defensa operativa: la primera estaba encomendada primordialmente a los alcaides y la segunda a los merinos, que encabezaban y mandaban la hueste en caso de guerra o de incursión enemiga ${ }^{62}$.

Como vemos, debemos situar el origen de la transición entre el sistema tradicional de tenencias y las nuevas demarcaciones en Navarra en el siglo XII, bajo los reinados de Sancho VI el Sabio y Sancho VII el Fuerte, y fue continuado, posteriormente, por Teobaldo I y por su sucesor Teobaldo II. La diferencia entre ambos modelos es clara y notoria: hemos pasado del sistema basado en múltiples tenencias, cuyo control se adjudicaba a barones con intereses particulares en el distrito y en donde su participación en la justicia, la defensa y la ordenación del territorio era más que dudosa en numerosas ocasiones - siendo en estos casos su presencia meramente testimonial—, a un sistema más controlado, dividido en distritos mucho más amplios y a cargo de los merinos nombrados y remunerados directamente por el monarca, por consiguiente, mucho más fieles, en principio, que los tenentes. La principal consecuencia de este nuevo sistema radica, aparte de una mayor simplicidad estructural, en que las rentas reales eran obtenidas por oficiales dependientes directamente del monarca y derivadas por completo al tesoro real; una vez recaudado todos los ingresos, una parte de estos eran redistribuidos para pagar los salarios de los cargos públicos ${ }^{63}$. Es decir, había un control y conocimiento de la recaudación de los ingresos y, a su vez, de los correspondientes salarios de los agentes reales.

La reforma administrativa obligó a sustituir a los ricoshombres por oficiales de mayor fidelidad. Para ello, se propició el ascenso social de hidalgos e infanzones pertenecientes a la baja nobleza que se integraron en los nuevos cargos del gobierno ${ }^{64}$. A pesar de que los grandes barones del reino fueron apartados de los principales cargos administrativos, siguieron siendo beneficiarios de concesiones regias aunque no de la misma manera en la que habían sido gratificados hasta ahora. La denominación de honor que aparece en muchos documentos de este reinado, tiene ahora el sentido de

\footnotetext{
${ }^{62}$ Martinena Ruiz, J. J., Castillos reales..., p. 69.

${ }^{63}$ Recuérdese que, anteriormente, los ingresos eran recaudados por los tenentes (o en su caso el alcaide) y eran divididos generalmente - aunque no siempre - a partes iguales entre el rey y él. Ver LACARRA DE Miguel, J. M., «Honores y tenencias..., pp. 121 y 139. Aunque estas cantidades podían verse radicalmente modificadas dependiendo de las circunstancias, como observamos en los casos de Artajona, Larraga, Mendigorría y Miranda de Arga. El reparto de la pecha de estas ciudades beneficia fundamentalmente al ricohombre el cual obtiene entre el 70 y el $85 \%$ del total de lo recaudado: en Mendigorría de los 3.640 sueldos que se iban a recaudar del impuesto, 3.000 sueldos se los quedaba el barón mientras que los otros 640 restantes iban dirigidos al monarca; en Miranda de Arga se especifica que se debían recaudar 4.200 sueldos, de los cuales 3.000 sueldos irían destinados al ricohombre que tenía la honor y los otros 1.200 al rey; en Artajona y Larraga, por último, los habitantes tenían que pagar 7.000 sueldos, de los cuales 6.000 se los quedaba en ricohombre mientras que los 1.000 restantes se los quedaba el rey. Ver Jimeno Jurío, J. M.; Jimeno Aranguren, R., Colección documental ..., doc. núm. 56, 57, 58, 59; FERnÁNDEZ DE LARREA RojAs, J. A., «La conquista castellana de Álava, Guipúzcoa y el Duranguesado (1199 y 1200)», Revista Internacional de Estudios Vascos, 45-2, (2000), pp. 430-431. Sin embargo, al ser el tenente el encargado de dicho deber, el rey no tenía un conocimiento exhaustivo de la cantidad recaudada, por lo que no podemos descartar que el noble que disfrutase de la honor ocultara una parte para sí. Por ello, el reparto le podía resultar en numerosas ocasiones perjudicial al rey.

${ }^{64}$ RAMirez VAQUero, E., «De los Sanchos..., p. 403.
} 
lotes de rentas de la corona sobre la base de un territorio. En realidad, esta denominación no es más que una reminiscencia de la época anterior, en la que los diferentes distritos territoriales eran confiados a un barón, que representaba al monarca y percibía por sus servicios una parte de los derechos señoriales del rey en dicha demarcación. Las rentas asignadas a estos ricoshombres, suponían ingresos importantes, en su mayoría en especie, que se llamaron caverías y estaban destinados para mantener a un caballero con su séquito. Los parientes de aquellos - caballeros o infanzonesdisfrutaban también de rentas reales, denominadas mesnaderías, pero suponían una cantidad menor que las anteriores y casi siempre se pagaban en metálico ${ }^{65}$. Por lo tanto, se ponía en marcha un nuevo sistema de colaboración militar con el monarca por medio de la entrega de feudos de bolsa, esto es, a cambio de las rentas los nobles debían acudir al ejército real con su séquito particular ${ }^{66}$.

Al hilo de lo arriba señalado, Iñigo Mugueta apunta que los antecedentes de la transformación de la administración navarra no se sitúan en el reinado de Teobaldo I, sino que nos tenemos que remontar a los reinados de Sancho VI y Sancho VII el Fuerte. Dicho autor llega a afirmar que «los nebulosos reinados de Sancho VI y Sancho VII parecen tener la clave de la evolución desde las honores hacia las caverías o caballerías» ${ }^{67}$. Según él Sancho el Sabio fue el pionero en confiar el gobierno del reino y las reformas administrativas en expertos ajenos a la alta nobleza como son el merino y el intendente mayor. Por su parte, Sancho VII el Fuerte trató de eliminar los cohesionados patrimonios de la alta nobleza, que ostentaba la jurisdicción sobre los distritos, y sustituirlos por lotes dispersos y rentas que reducían el poder de los nobles. Pero no fue hasta la primera mitad del siglo XIII cuando los reyes de la dinastía de Champaña tuvieron capacidad de prescindir de las antiguas tenencias y comenzar a poner en marcha un nuevo sistema de colaboración militar con el monarca por medio de la entrega de feudos de bolsa ${ }^{68}$.

Al igual que ocurría durante el reinado del rey Fuerte, en época de Teobaldo I se constatan entregas de castillos formalizadas mediante el rito del homenaje, en los que constatamos un lenguaje típico feudal.

Uno de estos casos es el de Guillermo Pérez de Castejón, quién prestó en julio de 1244 homenaje al rey por el castillo y la villa de Castejón, el cual se comprometía a

\footnotetext{
${ }^{65}$ GARCía ARANCÓN, M. R., La dinastía ..., pp. 142-143; GARCíA ARANCÓN, M. R., «Los ricos-hombres navarros y la realeza a mediados del siglo XIII», en Estudios dedicados a la memoria del profesor L. M. Díez de Salazar Fernández, T. 1, AYerbe IRÍBAR, M. R., Universidad del País Vasco, 1992, pp. 197-198. 66 Mugueta Moreno, I., «La nobleza en Navarra (siglos XIII-XIV)», en Iura Vasconiae: revista de derecho histórico y autonómico de Vasconia, 4, (2007), pp. 231 y 274.

${ }^{67}$ Mugueta Moreno, I., «La nobleza..., p. 200.

${ }^{68}$ Mugueta Moreno, I., «La nobleza..., pp. 198-199 y 231; ForTún PÉREZ DE CiRIZA, L. J., «Los fueros menores y el señorío realengo en Navarra (siglos XI-XIV)», Príncipe de Viana, 176, (1985), pp. 618-619, $630-631$ y 644.
} 
«façer seruicio lealment a todo rei de Nauarra» ${ }^{69}$. En noviembre del mismo año era Fortaner de Alascún el que prestaba homenaje por el castillo de Sádaba, el cual le había sido retirado en época de Sancho VII por haberle hecho, junto a sus hombres, «muitas roberias et muitos males» ${ }^{70}$. Además, tenemos constancia de otros dos vínculos de vasallaje, en los cuales se especifican la duración de la donación del castillo. En enero de 1237 Teobaldo I hace una donación vitalicia a Adán de Sada del castillo y la villa de Javier, mientras que en abril del mismo año encomienda para doce años a Martín Sanz de Viana el castillo de Asa a cambio de un tributo anual de veinte libras de sanchetes, y con la obligación de plantar una viña y hacer mejoras en dicho castillo ${ }^{71}$.

En el mismo reinado, pero bajo un contexto totalmente diferente, encontramos dos entregas de castillo en el área de Ultrapuertos realizados mediante sendos homenajes. Uno es el caso de Arnaldo Guillén de Agramont, quien renovó en 1237 el homenaje al rey Teobaldo I por el castillo de Agramont que hiciera su ascendiente Biviano de Agramont en 1203:

«In Dei nomine. Sepan todos aqueillos qui son e qui son por venir que yo don Analt Guillem d'Agramont so hombre lige, ante todos omnes, de meo seynnor don Thibalt, por la gracia de Dios rey de Navarra, comde palazino e de Champaña e de Bria, e tiengo d'eil ligement el castieillo d'Agramont con todas sus pertinencias, e viengo de conoscido e de manifest que io e todos aqueillos qui serán sennores del castiello d' Agramont por uos nuestro señor don Thibal, por la gracia de Dios rey de Navarra, e por todos aqueillios qui regnaran enpues uos en el regno de Navarra e por todo vuestro mandamiento $(\ldots) \gg^{72}$.

Otro de estos casos es el de Ramón Guillén, vizconde de Soule, que prestó homenaje al rey de Navarra por el castillo de Mauleón, pero respetando al mismo tiempo su lealtad al rey de Inglaterra: «ego super hoc deveni homo ligius ipsius Theobaldi regis Nauarre, salva ligeitate domni regis Anglie» ${ }^{73}$. La adscripción de estos castillos al reino de Navarra responde a la implantación de la soberanía navarra sobre Ultrapuertos. Sin embargo, estos homenajes se inscriben dentro de un sistema de lazos vasalláticos de extrema complejidad, habitualmente enmarañado y confuso, propio de la feudalidad del Midi. En este sentido, los nobles aquitanos —entre los que se sitúan Arnaldo Guillén de Agramont y Ramón Guillén vizconde de Soule_-, señores directos de sus tierras, pondrán al servicio del rey de Navarra sus castillos pero salvando el deber y servicio hacia otros soberanos, lo que debe entenderse en el contexto más amplio del choque de intereses entre los Plantagenêt y los Capetos ${ }^{74}$.

\footnotetext{
${ }^{69}$ Martín GonzÁlez, M., Colección Diplomática de los Reyes de Navarra de la Dinastía de Champaña. Teobaldo I (1234-1253), Eusko Ikaskuntza, (Col. Fuentes documentales medievales del País Vasco, n. ${ }^{\circ}$ 11), San Sebastián, 1986, doc. núm. 101.

${ }^{70}$ Martín GonzÁlez, M., Colección Diplomática..., doc. núm. 107.

${ }^{71}$ Martín GonZÁlez, M., Colección Diplomática..., doc. núm. 40 y 56.

${ }^{72}$ Martín GonZÁlez, M., Colección Diplomática ..., doc. núm. 67.

${ }^{73}$ MARTín GonZÁlez, M., Colección Diplomática ..., doc. núm. 10.

${ }^{74}$ Herreros LopeteguI, S., Las tierras navarras de Ultrapuertos (siglos XII-XVI), Gobierno de Navarra, Pamplona, 1998, pp. 66-113.
} 
Es difícil comprender los pactos de vasallaje de época del primer rey de Champaña, ya que no sabemos si pertenecen al viejo sistema de tenencias o a la nueva realidad que se estaba definiendo. Como hemos comentado más arriba, estos documentos tienen un lenguaje típico feudal, pero debemos tener presente, al mismo tiempo, que nos situamos en una fase de transición entre los dos sistemas. Podemos pensar que aquellos vasallajes realizados antes del año 1238 -último año en el que se constatan en los documentos las listas de tenentes - ${ }^{75}$, podrían suponer la dotación de una tenencia, y, en cambio, los realizados posteriormente supusieran una alcaidía ${ }^{76}$. Ahora bien, estas no son más que conjeturas. Por ende, no podemos esclarecer si mediante el vasallaje al rey, estos barones se convertían en tenentes del distrito cuyo castillo les había sido donado, o por contra, en meros alcaides.

\subsection{El caso de Estella: un proyecto piloto}

Como ha quedado detallado anteriormente, debemos situar el origen del sistema de alcaidías y merindades en Navarra antes de la llegada de la dinastía de Champaña. En esta línea, gracias al análisis de la documentación recogida por José María Lacarra en la Colección Diplomática de Irache. Volumen 1 (958-1222), podemos pensar que los antecedentes de la creación del nuevo sistema institucional podrían remontarse, como mínimo, a inicios del siglo XIII, es decir, al reinado de Sancho VII el Fuerte. La utilización de la documentación del monasterio de Irache no es nada casual, dada su cercanía geográfica a Estella, ya que muchos testimonios escritos relativos a la historia de dicha localidad fueron a parar a este monasterio.

Nuestro punto de partida será la citada localidad de Estella, donde se observa un fenómeno muy curioso: desde el inicio del siglo XIII desaparece por completo la figura del tenente, quedando solo el alcaide del castillo, cuyo nombramiento recaía principalmente en nobles de segunda categoría, es decir, miembros de la nobleza media al margen de las grandes familias de magnates del reino.

De hecho, el último tenente constatado propiamente dicho fue Diego López de Haro $^{77}$ en 1201-1202, señor de Vizcaya, quien, en principio, no pertenecía a la nobleza navarra stricto sensu, por entonces enemistado con Alfonso VIII de Castilla. Diego López no aceptó que Alfonso VIII repoblara la villa de Miranda de Ebro con los habitantes del vecino lugar de Bardauri, que era un señorío de su propiedad, lo que le llevó a desnaturalizarse y pasarse al servicio del monarca navarro, el cual, por su parte, tenía escasos motivos para simpatizar con el rey de Castilla ${ }^{78}$. Sancho VII el Fuerte, aprovechándose de esta situación le instaló en Estella, una de las plazas más importantes

\footnotetext{
${ }^{75}$ Estos son los casos de los anteriormente citados Arnaldo Guillén de Agramont, Ramón Guillén, Adán de Sada y Martín Sanz de Viana. Ver Martín GonzÁlez, M., Colección Diplomática..., doc. núm. 67, 10,40 y 56.

${ }^{76}$ Estos son los casos de Guillermo Pérez de Castejón y Fortaner de Alascún. Ver MARTín GonZÁLEZ, M., Colección Diplomática ..., doc. núm. 101 y 107.

${ }^{77}$ LaCARRA De Miguel, J. M., Colección diplomática ..., doc. núm. 225.

78 Fortún PÉREZ DE CIRIZA, L. J., «La quiebra de la soberanía navarra en Álava, Guipúzcoa y el Duranguesado», Revista Internacional de los Estudios Vascos, 45-2, (2000), nota 127.
} 
del reino, la cual defendió en el asedio que los reyes castellano y leonés emprendieron en dicha localidad en el año $1202^{79}$. No es casualidad que Sancho VII situara a este noble en Estella en 1201; el recuerdo de la conquista de Álava, Guipúzcoa y el Duranguesado por parte del ejército castellano era todavía muy reciente - ocurrió entre 1199-1200 - por lo que el rey navarro no dudó en situar al reputado Diego López de Haro al frente de una de las plazas estratégicas del reino para defenderla de otro inminente ataque castellano, como así sucedió ${ }^{80}$. Una vez que este noble abandonó el cargo, creemos que en Estella actuaron alcaides o castellanos, merinos, alcaldes, prepósitos, y bailíos, pero nunca más tenentes.

Ciertamente, la documentación plantea algunos interrogantes. Por ejemplo, en un documento fechado en 1203, encontramos un merino real, Iñigo de Gomacín, pero al que se le intitula al mismo tiempo tenente de Estella: «Enecho de Gomaçiain, merino regis, tenente Stella» ${ }^{81}$. Resulta particularmente significativo, para lo que aquí nos atañe, el caso de Iñigo de Gomacín, que consta como merino del rey Fuerte al menos entre los años 1203 y 1232. En el año 1203, aparecerá en otro documento como merino y tenente bailiam Tutele, y en 1204 se le menciona como merinus per tota Navarram y tenente de Peralta ${ }^{82}$. Este hecho es insólito en la documentación de este reinado, es decir, no encontramos otro caso en el que una misma persona ejerza como tenente y merino a la vez, dos cargos que por sus características parecen ser incompatibles. Esto nos lleva a pensar, volviendo al caso de Estella, que la denominación de tenente es una reminiscencia de la época en que la Estella era concedida por manum regis a un barón, y que la función que realmente ejercería sería la de merino. Además, esta idea coge fuerza si tenemos en cuenta que en casi todos los demás documentos en los que va a aparecer este personaje se le intitula solamente merino ${ }^{83}$.

En cuanto a los alcaides, el primero que encontramos en el reinado del rey Fuerte es Ochoa de Leorin en $1195^{84}$. Tampoco encontramos dificultades para identificar al segundo alcaide de Estella en 1201: «Dominicus castellan alcalt» ${ }^{85}$. La cuestión se embrolla a partir de aquí. En un documento de 1204 encontramos a Iñigo Salinas en el que aparece como «tenente castrum Stelle» ${ }^{86}$. En este sentido, lo que nos genera la duda es precisamente la mención, inusual hasta ahora, de la tenencia del castillo de dicha localidad; es decir, en cartas reales anteriores la nomenclatura del tenente iba seguida

\footnotetext{
79 LaCARRA De Miguel, J. M., Historia política del Reino de Navarra, desde sus orígenes hasta su incorporación a Castilla. T. 2, Caja de Ahorros de Navarra, Pamplona, 1972, p. 101; FORTÚN PÉREZ DE CIRIZA, L. J., «La quiebra..., p. 485.

${ }^{80}$ Para todo lo relativo a la conquista de Álava, Guipúzcoa y el Duranguesado ver FERNÁNDEZ DE LARREA RoJAS, J. A., «La conquista..., pp. 425-438 y ForTún PÉREZ DE CIRIZA, L. J., «La quiebra..., pp. 439-494.

${ }^{81}$ LaCARRa de Miguel, J. M., Colección diplomática ..., doc. núm. 232.

${ }^{82}$ RAMIREZ VAQUERO, E., «De los Sanchos..., p. 403.

${ }^{83}$ Constatamos a Enecho de Gomacín en Estella entre 1203 y 1216 . Ver LACARRA DE MiguEL, J. M., Colección diplomática ..., doc. núm. 232, 234, 236, 238, 239, 248, 249, 251, 254, 255, 262, 264, $269,272$.

${ }^{84}$ LaCARRA De Miguel, J. M., Colección diplomática ..., doc. núm. 221.

${ }^{85}$ LaCARRA de Miguel, J. M., Colección diplomática ..., doc. núm. 225.

${ }^{86}$ LaCARRA DE Miguel, J. M., Colección diplomática ..., doc. núm. 235.
} 
del nombre de la localidad, sin ningún tipo de referencia al castillo ${ }^{87}$. El hecho de que en este documento se especifique la fortaleza, como es usual en los casos de los alcaides, nos puede indicar que en realidad Iñigo Salinas era un castellano, quien estaría a cargo de la fortaleza de Estella.

Siguiendo la cronología, creemos que Fortún de la Puente fue alcaide de Estella entre los años 1209 y 1220, aunque en este caso la documentación es otra vez poco esclarecedora. El cargo que ocupaba este noble aparece de diferentes maneras: «tenente castellum de Stella», «alckayet», «dominator castro Castelle in Stella» y «tenentem castrum Stelle et thesaurum ibidem per manum regis» ${ }^{88}$. La que más nos llama la atención es la última de ellas en la que además de aparecer la ya comentada referencia de la «tenencia del castillo», se suma la de «per manum regis». Aunque no es extraño que un alcaide asuma su cargo mediante la ceremonia de homenaje de la immixtio manuum, por medio del cual se consumaba la relación feudo-vasallática entre el rey y el noble, sí que es cierto que es típico de los documentos en los que el rey concede feudos o tenencias a los grandes barones del reino. En todo caso, creemos que la clave es la mención «alcayet», lo que indicaría que a pesar de ser nombrado de maneras tan diferentes, Fortún de la Puente solo ocuparía el cargo de alcaide entre los años 1209 y 1220 .

Desde 1220 y el final del reinado de Sancho VII, es decir, 1234, encontramos tres alcaides más: Esteban, Martín Sánchez de Nogarol y Lorenzo de Vilatorta ${ }^{89}$. Parece ser, por lo que se desprende de un documento datado en 1232, que estos dos últimos actuaron al mismo tiempo en Estella: «Don Martin Santz de Nogarol, tenent lo castel de Stela per man del rei. Lorentz de Vilatorta, ali alchaiet». En este sentido, aunque parezca otra vez que estamos ante la forma clásica de la mención del tenente y su subordinado, el alcaide, el documento lo deja bien claro: mientras que uno es tenente del castillo, Lorenzo de Vilatorta era allí o «ali» alcaide ${ }^{90}$. La lógica nos lleva a pensar que Martín Sánchez de Nogarol sería el responsable máximo de la fortaleza que respondería por el castillo ante el rey, mientras que Lorenzo de Vilatorta sería su lugarteniente.

Como hemos dicho anteriormente, a partir de Diego López, encontramos merinos, alcaides, alcaldes, bailíos o prepósitos, pero no tenentes ${ }^{91}$. Es posible que el rey desease reservar para sí el mayor grado de control posible sobre Estella, apartándola del control de los magnates del reino. Teniendo en cuenta que desde el inicio del siglo XIII

\footnotetext{
${ }^{87}$ Un ejemplo puede ser el siguiente del año 1197: «Michaele de Lerat, tenente Sthellam». En JiMENO JuRío, J. M.; JiMENO ARANGUREN, R., Colección documental..., doc. núm 20.

${ }^{88}$ LACARRA DE Miguel, J. M., Colección diplomática..., doc. núm. 249, 252, 255, 266, 281, 284, 289 , 291, 298, 302 y 305; OstolazA, M. I., Colección diplomática de Santa María de Roncesvalles (11271300), Príncipe de Viana, Pamplona, 1978, doc. núm. 59.

${ }^{89}$ LaCARra DE Miguel, J. M., Colección diplomática de Irache. Volumen 2 (1223-1397), CSIC, Zaragoza, 1965, doc. núm. 343 y 353; Jimeno JuRío, J. M.; Jimeno ARANGURen, R., Colección documental..., doc. núm. 244.

${ }^{90}$ Jimeno Jurío, J. M.; Jimeno ARANGUREn, R., Colección documental ..., doc. núm. 244.

${ }^{91}$ Dada las características de este trabajo, hemos preferido dejar de lado el estudio de los alcaldes, prepósitos y bailíos.
} 
operaron tanto alcaides como merinos en lugar de tenentes, podemos suponer que Sancho VII empezó a utilizar por vez primera el sistema de alcaidías y merindades en dicha localidad.

Cabe suponer que una vez fallecido Sancho el Fuerte, Teobaldo I, para evitar cualquier tipo de discrepancias con los nobles locales, se decantó por nombrar alcaides y tenentes autóctonos. Así, entre las listas de tenentes y alcaides de los documentos de 1234 solo encontramos un francés, Roberto de Sezanne, quien curiosamente fue situado al frente del castillo de Estella. Esto nos puede indicar que, efectivamente, el sistema de tenencias se había dejado de utilizar previamente, y, por consiguiente, el hecho de que estuviera libre de cualquier tipo de enraizamiento señorial posibilitó el nombramiento de un noble francés en Estella ${ }^{92}$.

\section{CONCLUSIONES}

Recapitulando, a partir de los últimos años del siglo pasado una nueva línea de interpretación se inclina establecer los antecedentes del nuevo sistema de alcaidías y merindades antes de la llegada de Teobaldo I al trono de Navarra en 1234. Desde entonces se han destacado en varios trabajos, básicamente publicados por los historiadores Ángel Juan Martín Duque y Eloísa Ramírez Vaquero, las primeras alusiones a merinos del rey en el siglo XII, anunciando la idea de una puesta en marcha del nuevo sistema previa a la llegada de los reyes champañeses.

Tras hacer un seguimiento de los tenentes de Estella, creemos que somos capaces de situar, con mayor firmeza, los antecedentes del régimen de las alcaidías a inicios del siglo XIII, es decir, durante el reinado de Sancho el Fuerte. El último tenente constatado como tal es Diego López, quien ejerció la tenencia de dicha localidad durante los años 1201-1202. A partir de entonces, se documenta en Estella la presencia de otra clase de oficiales, pero nunca más tenentes. La aparición en la documentación posterior de referencias de oficiales encargados del castillo, «tenente castrum», y alcaides, creemos que es indicativo de que se estaba empezando a definir en dicha localidad el nuevo sistema. Por tanto, intuimos que Teobaldo I no partió de cero en sus reformas y que, en Navarra, podría haber sido el continuador y culminador de una línea de reforma administrativa iniciada, como mínimo, por el rey Fuerte.

Sabemos que es algo arriesgado defender la idea de que a inicios del siglo XIII estaba instaurado el nuevo régimen mediante el análisis de las menciones de los cargos oficiales, sin una prueba más fehaciente con la que poder contrastar la información. No descartamos que en futuras investigaciones se pueda encontrar entre la documentación un indicio más sólido, indicio que, haciendo acto de sinceridad, no hemos sido capaces de localizar. Aun y todo, pensamos que no es en absoluto disparatado pensar que una

${ }^{92}$ García Arancón, M. R., La dinastía..., pp. 41 y 50; MARtín GonZÁlez, M., Colección Diplomática..., doc. núm. 2. 
vez dejado el cargo Diego López, un tenente no perteneciente a la nobleza navarra en sentido estricto, Sancho VII experimentara en Estella la aplicación de un sistema distinto al presente en el resto del reino. De hecho, creemos que se daba un factor positivo para ello, puesto que al ser Diego López extranjero, y haber estado tan poco tiempo en la localidad (entre 1201 y 1202), sería muy difícil que existiera algún tipo de enraizamiento señorial por parte del barón en la villa del Ega, lo que a su vez facilitaría la introducción de nuevos oficiales.

En este sentido, cabe pensar que el rey Fuerte iniciara este cambio institucional para obtener un control más directo sobre dicha localidad. La importancia de mantener Estella bajo soberanía directa del monarca era doble: además de ser — con Tudela — una de las capitales del reino, en su castillo se guardaba el tesoro real y — quizá, tambiénun núcleo importante del archivo documental ${ }^{93}$. Así, Sancho VII, recordando la pérdida de Álava, Guipúzcoa y el Duranguesado y el posterior asedio de Estella, decidió aumentar su control sobre esta plaza estratégica mediante alcaides, nombrados y remunerados directamente por él y, por consiguiente, más dependientes que los tenentes de la alta nobleza, que gozaban de amplios derechos y garantías frente al monarca. Esta hipótesis toma fuerza si analizamos detenidamente la documentación. En uno de los documentos Fortún de la Puente es nombrado alcaide y, por ende, responsable, no sólo del castillo, sino también del tesoro ${ }^{94}$. La verdad que no hemos observado en ningún otro documento de este reinado en el que se haga una mención tan explícita al tesoro en estos casos. Al final del reinado de Sancho VII el Fuerte, concretamente en el año 1232, vemos otro caso inusual hasta la fecha: el nombramiento de dos cargos a la vez para defender el mismo castillo. Advertimos, pues, una necesidad por parte del rey navarro por proteger y afianzar su control y gobierno sobre una de las localidades más importantes del reino.

En definitiva, a través de este estudio pretendemos realizar una aportación al conocimiento sobre el cambio de control y gobierno que sufren los castillos navarros a lo largo de los siglos XII y XIII, exactamente entre los reinados de Sancho VII el Fuerte (1194-1234) y Teobaldo I (1234-1253).

\footnotetext{
${ }^{93}$ Existen constancias de que el primer rey champañés, Teobaldo I, contaba desde 1237 con al menos un fondo documental substancial en Estella. Cabe la posibilidad de que la documentación sita en esta localidad hubiera sido trasladada durante los reinados de los monarcas Teobaldo I y Teobaldo II cuando empezaron a instalarse en el palacio de Estella durante sus estancias en Navarra. Poco antes, durante el reinado de Sancho VII el Fuerte, el archivo «vivo» del rey, es decir, el que recogía su intensa actividad política, económica y patrimonial, estaba situado en Tudela. En este sentido, Tudela era la residencia regia por excelencia, principalmente durante los últimos años de vida del rey Fuerte, los cuales los pasó encerrado en dicha localidad. Sin embargo, teniendo en cuenta la subsecuente utilización del castillo de Estella como archivo documental de la corona navarra, no descartamos que, ya desde época del rey Fuerte, esta plaza estratégica funcionara también como sede de parte del archivo regio. RAMírez VAQUERO, E. (dir.), El primer cartulario de los reyes de Navarra. El valor de lo escrito / Le premier cartulaire des rois de Navarre. La valeur de l'écrit. T. 2, Gobierno de Navarra, Pamplona, 2013, pp. 2573.

${ }^{94}$ La mención literal es: «tenentem castrum Stelle et thesaurum ibidem». Ver LACARRA DE MIGUEL, J. M., Colección diplomática..., vol.1, doc. núm. 290.
} 